biology syllabus, and the other on the elementary science suggested by the School Certificate Investigators' Report as a compulsory subject at the School Certificate stage. This latter discussion will form the subject of a further report.

Visits were paid by various members to seventeen factories and Government scientific institutions in and around London. These included, among others, the Courtauld Institute of Biochemistry, the Paint
Research Station, Government Laboratories, the Royal Observatory, the Royal Aircraft Establish. ment, and the Royal College of Surgeons. These, together with the exhibition of scientific textbooks and apparatus, made a very full programme. Twenty. three publishers and thirty-nine manufacturers and thirty-five members exhibited.

The next annual meeting will be at Oxford under the presidency of Dr. N. V. Sidgwick. F. W. T.

\title{
Annual Meeting of the Mathematical Association
}

$\mathrm{T}^{\mathrm{H}}$ HE annual meeting of the Mathematical Association was held at the Institute of Education, London, W.C.1, on January 4-5, under the presidency of Prof. G. N. Watson. Discussions on the place of mathematics in the new central schools, on the interesting and novel suggestion that in the teaching of elementary geometry, solid geometry should precede plane geometry, and on the place of differentials in the teaching of the calculus, showed that the Association has not forgotten its primary purpose, the improvement-if necessary, the reform - of the teaching of elementary mathematics.

Under the title "Scraps from some Mathematical Note-Books", Prof. Watson delivered a lucid and stimulating presidential address. It was based on the diary in which C. F. Gauss (1777-1855), one of the greatest mathematicians of all time, recorded many of his discoveries; Gauss started keeping this diary at the age of nineteen, and it is remarkable that the majority of the hundred and fifty entries were made before 1801 .

The first entry is the discovery of the possibility of a ruler and compass construetion of the regular polygon of seventeen sides, a particular case of a more general problem to which Gauss himself gave a complete answer at a slightly later date. There are several entries referring to the quadratic reciprocity theorem; another, prefaced by a triumphant "Eureka", is equivalent to the result that every integer of the form $8 m+3$ is expressible as the sum of three odd squares. Other entries mentioned by Prof. Watson deal with continued fractions, the zeros of a Bessel function, and a function which is connected with the famous zeta function of Riemann. In connexion with this last entry, Prof. Watson pointed out that in a copy of Schulze's logarithm tables inscribed "Gauss, 1791", Gauss has made a note which can readily be interpreted as a statement that the number of primes less than a large number $x$ is approximately equal to $x / \log _{e} x$; this is the "prime number theorem", of which the first proofs were given by Hadamard and de la Vallée Poussin in 1896.

In addition to describing these striking results, Prof. Watson gave a brief account of the developments to which these results have led, concluding with a description of some remarkable numerical work connected with the prime number theorem which was carried out in 1933. His general aim was not only to honour Gauss but also to stress the importance to mathematicians of the dictum of N. H. Abel (1802-29) who, when asked how he had been able to accomplish so much in so short a time, replied: "By studying the masters, not the pupils".

Prof. E. H. Neville, professor of mathematics in the University of Reading, has been elected president of the Association for the forthcoming year.

\section{Research at the Cawthron Institute}

$\mathrm{T}$ HE Cawthron Institute at Nelson, New Zealand, was founded and endowed through the munificence of Mr. Thomas Cawthron, who was born in 1833, and after his death his trustees decided that a research institute for the investigation of agricultural problems should be established as the best means of carrying out his expressed desire. The Cawthron centenary lecture, "The Achievements of the Cawthron Institute", delivered on October 9 by Prof. T. H. Easterfield on his retirement from the directorship of the Institute, formed a fitting epilogue to the first Cawthron lecture, "The Aims and Ideals of the Cawthron Institute", given by him in 1917.

Beginning with the early work of the Institute, Prof. Easterfield said that one of the first problems to be attacked was the improvement of the fruit industry. A soil survey of the Nelson provinee was initiated, and the distribution and special characteristics of the soils studied with particular reference to fruit growing. The information thus gained led to recommendations with regard to soil treatment and cover cropping without which many orchardists would have been obliged to abandon their crops. Biological problems such as bitter-pit, black spot, woolly aphis and codlin moth were investigated concurrently. An insect, Aphelinus mali, was imported in 1920 for the control of woolly aphis and induced to breed in New Zealand. Its remarkable success is evidenced by the fact that it is no longer necessary to spray trees which formerly had suffered heavily. Such parasitic control is being extended with promising results to other insect and plant pests including the blowfly, which attacks lambs, and the piri-piri, a burr-producing plant which seriously reduces the commercial value of wool fleece. Much useful work has been done in controlling fungus diseases of fruit and flowers. In the work on black-spot, the main fungal disease of pip fruit, it has been found that infection can be controlled by spraying at a period, varying with the season, when ascospores are just about to be ejected by the fallen leaves of the previous year.

Prof. Easterfield gave further instances of researches which have resulted in outstanding increases in the production of fruit and other important crops, notably the control of brown rot in peaches, the improved fertilising of raspberries, the selection of soils for tobacco and lucerne, the steam sterilisation 
of tomato soils, and the cultivation treatment of barley. Discussing the extensive work on the mineral content of pastures, he said that the data so far recorded promise to have a very marked effect on the agricultural practice of the future, and emphasised the importance of supplementary fodder production for stock. Studies of stock ailments such as bush. sickness and xanthin (urinary) calculi of sheep have also yielded conclusive evidence indicating the means of controlling them. The first, due to nutritional deficiency of iron, has been shown to be due to lack of soluble forms of iron in the soil rather than in the pasture; stock appear to derive much of the iron they need by ingestion of the soil itself. It has also been shown that xanthin calculi can be avoided by the encouragement of English grasses and clovers, by suitable top-dressing, and by the supply of supplementary feeds.

Among other examples of the practical value of the work of the Institute, Prof. Easterfield referred to the economic importance of the investigations carried out on the reclamation of the extensive pakihi lands occurring chiefly in the more populated mining districts. Field plot studies have shown that it is possible to bring the land, supporting only fern and rush in its natural state, into a condition suitable for dairy farming at a cost as low as $£ 6$ per acre.

\section{The Japanese Seismic Sea-waves of March 3, I933}

$\mathrm{T}$ HOUGH we may have to wait some time for the complete reports on the great Japanese earthquake of March 3, 1933, some valuable papers have recently been published*, of which an abstract is here given. The earthquake occurred at about 2.32 a.m., Jap. Stand. Time, on March 3 (5.32 p.m. on March 2,

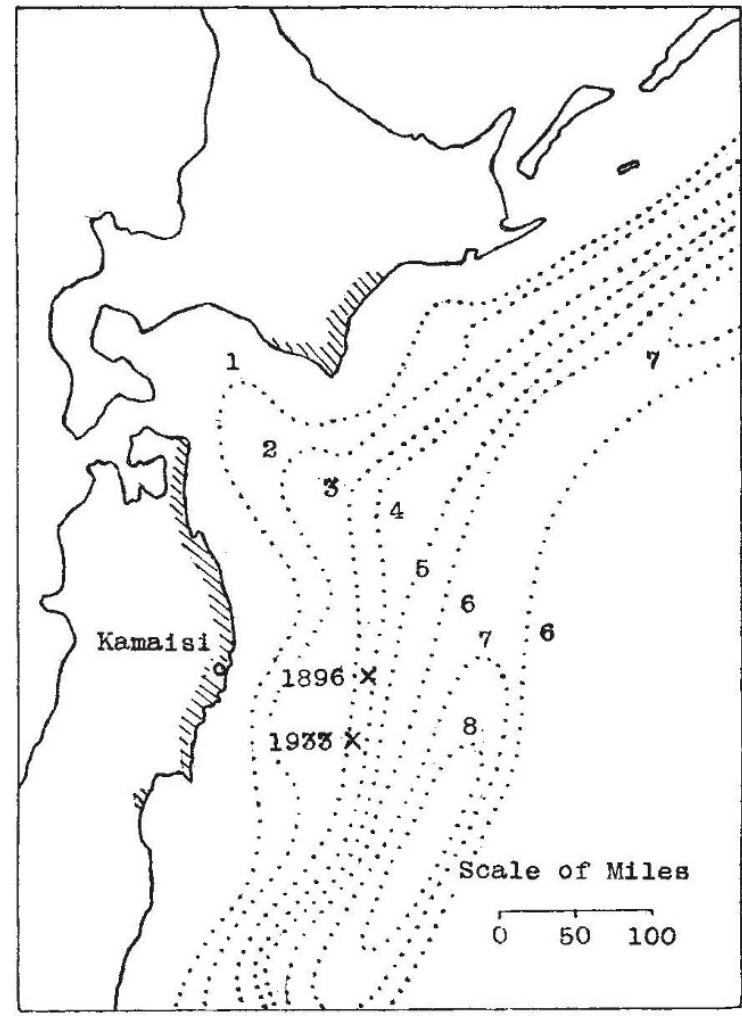

FIf. 1. Isobaths of the Japanese earthquake of March 3, 1933.

G.M.T.). From the records at stations connected with the Earthquake Research Institute, Prof.

* M. Ishimoto. Preliminary notes on the tunami of March 2, 1933 (G.M.T.), and an outline of the investigations now being made concerning it at the Earthquake Research Institute. Japan. J. Astron. Geophys., 11, 1-9; 1933.

T. Matuzawa, K. Kanbara and T. Minakami. Horizontal movement of water in the tunami of March 3,1933 , ibid., pp. 11-16.

A. Imamura and Z. Kawase. The Sanriku tunami of 1933 , ibid., pp. $17-35$.

T. Terada. Luminous phenomena accompanying destructive seawaves (tunami). Proc. Imp. Acad., Tokyo, 9, 367-369; 1933.

Notes on the prevention of damage from tunami. 'Issued by the Imperial Farthquake Council, 1933.
Ishimoto finds the epicentre to be in lat. $38 \cdot 2^{\circ} \mathrm{N}$, long. $144 \cdot 0^{\circ} \mathrm{E}$.; while the observations at Tokyo, according to Prof. Imamura, place it in lat. $38.5^{\circ} \mathrm{N}$., long. $143 \cdot 3^{\circ} \mathrm{E}$. The latter point is represented by the more southerly of the two crosses in the accompanying map (Fig. 1), the other being the epicentre of the great earthquake of June 15, 1896. The dotted lines on the map are isobaths in thousands of metres, and the two points, which are about fifty miles apart, both lie near the isobath of 4000 metres or about $2 \frac{1}{2}$ miles, on the northern slope of the Tuscaroora Deep, the depth of which exceeds five miles.

The point given above is that below which the movement of the crust-block began. It differs slightly, however, from the origin of the great sea-waves. Assuming the velocity of the waves to be $\sqrt{ }(g h)$ ft. per sec., where $h$ is the depth in feet, Mr. R. Takahasi has determined the position of the wavecentre from the times of arrival of the sea-waves at Miyako, Tyôsi and Tukihama, namely, lat. $38 \cdot 3^{\circ} \mathrm{N}$, long. $143 \cdot 6^{\circ} \mathrm{E}$.

Both points, however, being about a hundred miles from the coast, the shock, though widely felt on land, caused only slight damage along and near the coast. After an interval, ranging from 25 to 40 minutes, the great sea-waves swept over the shores shaded on the map, and drowned 3,022 persons, washed away 6,889 houses, besides destroying more than 8,000 boats and other vessels. In 1896, the earthquake was less severe than in 1933, but the waves were in most parts higher, and the destruction was far greater, 27,122 lives being lost and 10,617 houses washed away. In Hokkaido, the greatest height of the waves as shown by marks left on trees, posts, slopes, etc., was $15 \mathrm{ft}$. In the Main Island, it was $15 \mathrm{ft}$. at Kamaisi, the place that suffered most in 1896, but somewhat farther to the south, it rose to $62 \mathrm{ft}$. along the coast at Ryôri Sirahama (and $93 \mathrm{ft}$. inland) and $75 \mathrm{ft}$. at Hirota Atumari. The waves swept in with such velocity that a motor-boat from Kamaisi, with a speed of 12 miles an hour, could make no headway against them. Across the Pacific, they were recorded by mareographs at Honolulu, San Francisco and Santa Monica.

Mr. K. Musya has made an exhaustive study of the luminous phenomena seen as the waves came in. Among them is reported a strong flash of light that seemed to be emitted from the surface of the sea near the mouth of Kamaisi Bay. Prof. Terada shows that the most probable explanation of the flash is that the turbulence of the water in front of the 